\title{
Conference on the Magnetization of the Oceanic Crust Steers Future Research
}

PAGES 199-200, 202

Because marine magnetic anomalies arise from the combination of seafloor spreading and geomagnetic polarity reversals, they delineate a history of global plate motions and geomagnetic field behavior. Thirty years ago, interpretation of sea surface magnetometer profiles led to the plate tectonics revolution. Recent developments in high resolution magnetic studies are similarly changing our view of the structure and evolution of oceanic crust and beginning to answer basic questions concerning geomagnetic field behavior.

In response to these developments, the Conference on the Magnetization of Oceanic Crust was held September 21-24, 1996, on Orcas Island in Washington State. Forty-seven scientists representing 20 institutions in seven countries attended the conference, which was funded by the National Science Foundation, the Ridge Interdisciplinary Global Experiment (RIDGE), and the United States Science Advisory Committee (USSAC).

Major goals of the conference were defining hypotheses about magnetization of ocean crust that require testing; identifying new tools, analytical techniques, and field programs needed to carry out these tests; and finding ways to integrate the insights gained from new magnetic studies and techniques with the objectives of other scientific disciplines and with major research initiatives such as C-SEDI and RIDGE.

Although the discussion in the working groups established at the conference (see sections below) and plenary sessions was lively and animated, participants generally agreed on high-priority areas for research and on the approaches to these problems.

\section{Crustal Architecture and the Magnetic Source Layer}

The source of marine magnetic anomalies depends on the crustal architecture as well as physical and chemical processes that give rise to magnetism of the crust. All oceanic crust and upper mantle lithologies can apparently acquire some degree of remanent magnetization; thus, the key to identifying the source layer lies in rock magnetic studies of the stability, the timing of the acquisition of remanence, and the spatial distribution of magnetic isochrons within the crustal section. The internal structure of oceanic crust-an important record of oceanic crust formation, deformation, and alteration with age-remains poorly understood. Seismic data provide high-resolution images of the base of the extrusive layer, but they do not provide age correlations and cannot be related to individual volcanic sequences. Magnetic studies provide the temporal control and resolution necessary to define oceanic crustal architecture.

High-resolution magnetic surveys using deep-towed instruments and sensors mounted on submersible and autonomous vehicles (Figure 1) can determine the depthdependent shape of crustal isochrons, the geometry of individual volcanic units, and the timing of hydrothermal alteration associated with the accretionary process. Mapping of the magnetization distribution on near-vertical crustal exposures provides a unique view of extrusive crust formation and crustal isochron variation with depth. Mapping a single isochron completely through a deep crustal section would have a major influence upon models of deep crustal petrology and on hydrothermal cooling of the accreting system.

Various studies, including satellite magnetic surveys, studies of anomaly transition widths, rock magnetic studies of ophiolites and dredged rocks, and recent drilling of ODP Hole 735B in the southwest Indian Ocean, have produced evidence that the deeper crust, particularly the gabbroic section, may contribute significantly to the anomalies. At the 735B site, lineated magnetic anomalies are present, even where the upper extrusive layer has been completely removed to expose the gabbroic section. More complete vertical cross-sections of exposed oceanic crust are known to exist at Hess Deep, Blanco Trough, Endeavor Deep, and Pito Deep in the Pacific Ocean, and Kings Trough and Royal Trough in the Atlantic Ocean, and these sections were recommended for study. Work in the Atlantic Ocean suggests that intrusive rocks are frequently exposed at the inside corners of ridge segment offsets and transforms, and surficial exposures of lower crustal rocks with lineated magnetic anomalies may be a common feature of slow spreading ridges.

\section{Short-Term Variability in Oceanic Crustal Magnetization}

In addition to the well-established pattern of large-scale polarity reversals, the lineated nature of some small-scale anomalies is well documented and may have a geomagnetic origin. New data presented at the conference that was based on a deep-tow survey of Anomaly 5 in the northeast Pacific Ocean show a coherence of short-wavelength anomaly variations in the near-bottom field between two spreading corridors that were separated by over $100 \mathrm{~km}$. This working group identified the following important issues: determining whether small lineated anomalies are intensity fluctuations or polarity reversals, identifying the origin of the Central Anomaly Magnetic High (CAMH) that overlies most spreading centers, and using fine-scale anomalies to examine crustal accretionary processes.

The CAMH is clearly visible in sea surface profiles. The $2-4 \mathrm{~km}$ wavelength of this feature in near-bottom profiles requires an abrupt decrease in the magnetization of the upper crustal layers with age-a phenomenon opposite to the increasing extrusive layer thickness with age that is interpreted from seismic studies. Both low temperature alteration and paleointensity variations have been proposed as plausible causes for the magnetization contrast producing the CAMH. The origin of the CAMH can be addressed through near-bottom magnetic surveys and densely spaced flow line sampling in regions where seismic data that define the thickness of Layer 2A are available.

When linked with other high-resolution geological data, the pattern of near-bottom magnetic anomalies can be used to constrain crustal accretion and magmatic supply. For example, association of the CAMH provides critical identification of the neovolcanic zone. Correlation of magnetic anomaly amplitudes with high-FeTi lavas suggests that geochemical variations could be remotely mapped with magnetics. Similarly, the pronounced reduction in magnetization associated with hydrothermal alteration suggests that near-bottom magnetic surveys could be used to delineate the extent of subsurface hydrothermal circulation.

\section{Long-Term Variability of Oceanic Crustal Magnetization}

Polarity intervals vary in duration from the 37-Ma-long Cretaceous Normal Superchron (CNS) to individual chrons lasting only a few thousand years. The amplitude of seasurface anomalies is also extremely variable and the source of these variations is not well understood. In general, oceanic crustal magnetization decreases markedly from a maximum at the ridge crest to a minimum at 10-20 Ma. Crustal magnetization then increases with age to a peak during the Cretaceous superchron (83-120 Ma), although sea surface profiles suggest an additional maximum in the early Cenozoic. Prior to the Cretaceous superchron, oceanic crustal magnetization has intermediate values from 120 to $150 \mathrm{Ma}$, which decrease systematically from 150 to $170 \mathrm{Ma}$ into the Middle Jurassic, 


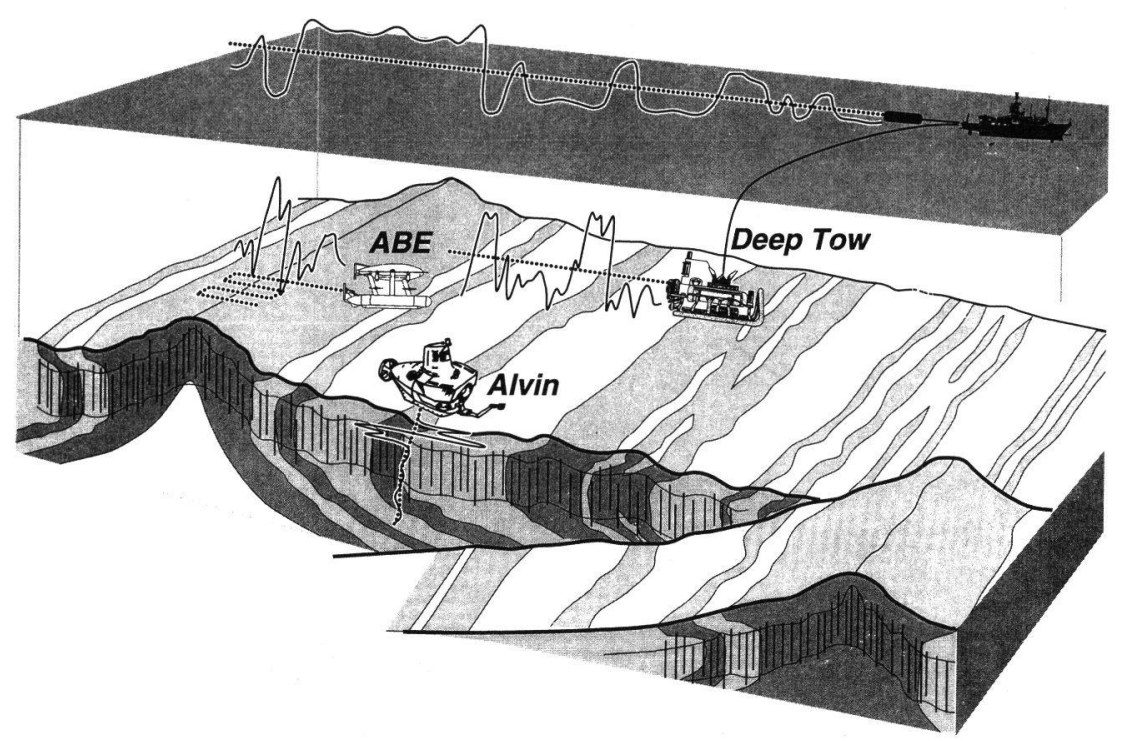

Fig. 1. Schematic diagram showing the types of surveys used in the study of oceanic crustal magnetization. Sea surface magnetometer surveys determine the age of the crust, define the tectonic history of the region, and provide the essential geological context for higher-resolution studies. Near-bottom magnetometer surveys with wired (deep-tow and Jason) and wireless remotely operated vehicles (e.g., the Autonomous Benthic Explorer) provide high-resolution data needed to characterize geomagnetic field behavior and crustal alteration processes. Magnetometer sensors mounted on submersibles (e.g., ALVIN) can continue these high-resolution surveys on vertical crustal sections exposed at fracture zones, providing a window into the deeper crustal sections. Finally, drilling (not shown) by the Ocean Drilling Program and small over-the-side rock drills provide critical rock samples needed to interpret the potential field studies.

when the amount of oceanic crust of this age becomes vanishingly small.

Whether field intensity is correlated with reversal rate remains a fundamental question. Limited data suggest that the high ocean crust magnetization associated with the long, single-polarity CNS may be related to a high paleofield strength, although global compilations of land-based paleointensity data (surprisingly) do not show these variations. If the paleofield intensity is the source of large-scale variations in ocean crust magnetization, it should be reflected in both continental and oceanic environments. If, however, the observed changes are specific only to ocean crust, then other processes, such as the inhibition of low-temperature oxidation of magnetic minerals or a systematic geochemical variation of the crustal rocks, should be investigated. The CNS period has the highest priority for this problem, since it is the longest well-char- acterized polarity interval. Conference participants expressed strong support for an ODP drilling transect across the CNS in the Pacific.

\section{Future Tools and Methods}

Conference participants agreed that future studies in marine magnetics require data with higher resolution than are currently available from sea surface studies. The working groups identified several promising areas for future marine magnetic studies:

- high-resolution, near-bottom surveys, including the construction of additional, inexpensive deep-tow magnetometer packages;

- routine addition of magnetic sensors to submersibles, remotely operated vehicles, and autonomous underwater vehicles;

- development of analytical techniques for using vector and gradient data obtained by these three-component sensors;
- development of wire line rock drills to obtain in situ oriented samples from exposed bare rock areas;

- wider use of satellite magnetometer data to define the long-wavelength component of the anomaly field; and

- greater involvement of the marine magnetics community in planning ODP crustal legs.

Initiatives covering most of these areas are presently under way, and there is considerable enthusiasm for forming a working group on ocean crustal magnetization within the new Ocean Drilling Program structure.

While near-bottom magnetic observations are critical to advancing the next generation of oceanic magnetic studies, satellite and sea surface magnetometer data are needed to analyze regional variability in oceanic crustal structure and to provide a tectonic context for the proposed high-resolution studies. The synoptic view from space allows a continuous, high-fidelity anomaly field to be constructed for the wave band of 300-3000 km-a section of the spectrum that is not available otherwise. Low-altitude satellite measurements, particularly below $300 \mathrm{~km}$, will be valuable for studies of regional variations in anomaly amplitude. Finally, conference participants expressed great concern about the status of magnetic anomaly data from the extensive (classified) sea surface and aeromagnetic surveys conducted by the U.S. Navy over the last 30 years. These data, which fully cover almost all of the ocean basins, are presently archived on short-lived magnetic tape, and their finite shelf life is being approached. Conference participants expressed strong support for the release of these data by the U.S. Navy to the World Data Center.-H. Paul Johnson, University of Washington, Seattle; Dennis V. Kent, Lamont-Doherty Earth Observatory, Palisades, N.Y.; Maurice A. Tivey, Woods Hole Oceanographic Institution, Woods Hole, Mass.; Jeffrey S. Gee, Scripps Institute of Oceanography, La Jolla, Calif.; Roger L. Largon, Graduate School of Oceanography, University of Rhode Island, Narragansett; Robert W. Embley, National

Oceanographic and Atmospheric Administration/Pacific Marine Environmental Laboratory, Newport, Ore. 